\title{
DEVELOPMENT OF AN ELECTRIC BICYCLE FOR A SHARING SYSTEM IN PRAGUE
}

\author{
William Deleenheer ${ }^{a, *}$, LukÁŠ JÁneš $^{b}$, Akshaya JayakumaR $^{b}$ \\ ${ }^{a}$ KULeuven, Faculty of Industrial Engineering, Gebroeders De Smetstraat 1, 9000 Gent, Belgium \\ ${ }^{b}$ Czech Technical University in Prague, Faculty of Transportation sciences, Department of vehicle technology. \\ Konviktská 20, 11000 Prague \\ * corresponding author: william.deleenheer@gmail.com
}

\begin{abstract}
By means of a development of an e-bike sharing system the Electromobility Project wants to provide an alternative way of comfortable transportation for students and staff of the CTU, primarily to commute between different campuses. The research for this project contains at least three different fields of study, namely electric vehicle and docking station development, intelligent transport systems and management and economics of transportation and telecommunication. After briefly stating general requirements for the sharing system, this paper focuses on the development of the electric bicycle. First an ideal bike design is defined. Then necessary motor power and battery capacity are calculated by estimating characteristics of cycling in Prague. A prototype was developed by converting a normal bicycle to an electric bicycle. Being equipped with devices for e-bike monitoring, controlling and data recording for a post trip analysis, this prototype is also intended to have an educational value for future students in the project. Results consist of an electrical bicycle configuration that matches the requirements and a sketch of an ideal e-bike for this project.
\end{abstract}

KEYWORDS: e-bike sharing, requirements, e-bike design, motor power, battery capacity.

\section{INTRODUCTION}

The demand and supply of electric bicycles is a fastgrowing market. A market study on e-bike purchasing has increased for this year, mainly in the Netherlands, Denmark and Germany. It is said that the market first concentrated on the Netherlands and Germany due to its overall size.

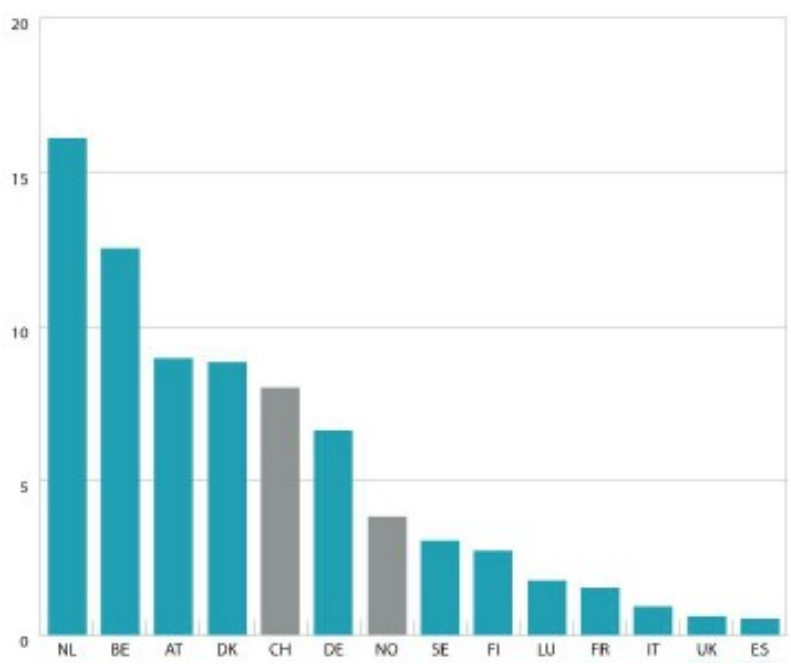

Figure 1. E-bike unit sales per 1000 inhabitants in 2015, data from ECF Advocacy group's publication [1].

But eventually the per head market demand increase in Switzerland, Austria, Denmark proved to be relatively stronger. Customers start to have innu- merable options to combine any kind of bicycle with different sorts of batteries and motors at a wide range of prices. Nevertheless, to compose a suitable e-bike for a sharing system is less easy.

First of all, a responsibility that comes with owning a bicycle lies not with the end user anymore and thus the user has no incentive to care for it or maintain it. And second a sharing system takes into account many bicycles thus the cost of maintenance or theft as well as an initial investment of one e-bike should be as low as possible. Furthermore, there are some requirements for a successful and economically viable sharing system, mostly regarding user experience, such as safety and comfort. This paper has tried to list these requirements and develop an electric bicycle accordingly.

\section{General ReQuirements FOR the SHARING SYSTEM}

Determining the requirements for a viable e-bike sharing system for the CTU but also for Prague in general has been carried out in three ways. In the first place, there was an existing project vision that originated both in the project goal as in earlier research. Then more detailed requirements were defined by a research of existing examples in the academic world and in the market. Finally, the requirements as for the station and software for an initial pilot project were summarized. 


\subsection{PROJECT VISION}

The primary goal of this project is to provide a more efficient way of transportation for students and staff of the faculty of Transportation Science as a means to commute among different faculty buildings. The challenge exists in achieving this goal without losing comfort that comes with using a currently available public transport system. The concept of comfort in this context can be specified in four clear requirements:

- Minimal human physical effort,

- Protection against bad weather conditions,

- Possibility to transport certain cargo,

- Easy access to the system.

A priority condition for all other requirements is obviously safety, all the more because cyclists are vulnerable road users and the bicycle infrastructure is still limited in Prague.

\subsection{MARKET RESEARCH}

Market examples and previous experience with both conventional bike sharing schemes as well as a few existing e-bike sharing schemes such as Go bike[2], Bewegen.com [3, Bonopark [4] and cycleUshare [5] were researched to define components of a successful e-bike sharing system. Another useful source was the experience of the Institute of Transportation and Development Policy (ITDP) 6 with planning and exploitation of bike sharing systems. The following characteristics have been found repeatedly and are here briefly summarized:

- Integrated and theft protected e-bike components (motor, battery, chain, lights, wires, HID, automated lock);

- Ergonomic bicycle design (step-thru frame with adjustable saddle);

- User friendly bicycle checkout and payment procedures;

- High station density (10-16 stations for every square kilometre for conventional bikes);

- Many bicycles (10-30 bikes for every 1,000 residents for conventional bikes);

- Large coverage area (10 square kilometres for conventional bikes);

- Others: auxiliary (digital) lock, GPS tracking, modular docks.

Discussable options are a use of high-end integrated components such as internal gears, belt drives or puncture free tires that reduce maintenance or theft costs but require higher initial investment.

The university of Brighton in UK conducted a similar e-bike research. The research aimed to understand user needs and to develop a system design necessary to start a fleet of e-bike program. The main outcome was a development of a "smart tracking system" which was implemented in a few e-cycles and proved successful. The system autonomously recorded and transmitted a bikes position, route, level of assistance required in real time and then sent it all in an online interface which was used for both research analysis and participant review. This proved to be an efficient solution for the fleet management and theft control. Most of the users were daily commuters to office, the surveys revealed that most of them had found it easy to use and that it was something which had not disturbed or damaged their clothing much.

\subsection{Station And SOFTWARE REQUiREMENTS}

This project opted for a system in which the batteries have to be rented and plugged onto a bike by the user. This concept of battery charging and vending machine was first used in the "cycleUshare project" $[5$. The main advantage is that the station can have more batteries than bicycles and thus always has a fully charged battery for the user. In this concept all the batteries are stored in one charging box which protects the batteries from weather conditions and theft. This way the charging system and the bicycle docks can be made much cheaper compared to a more common way in which every dock needs a charger and the battery is integrated in the bicycle. Another advantage is that the batteries, which mostly have a shorter life span than the bicycles themselves, can be maintained or replaced very easily. The biggest disadvantage is a decreased ease of use since the check in and check out procedure involves handling a battery. More experience is needed to determine an exact opportunity cost of this concept.

The system is required to be an intelligent system. This includes necessity of mutual communication between the user, server, station, bicycle and battery. The tools to be used for this communication are ISIC student cards (RFID), GPS tracking, RFID controlled locks, HID's, system managing software and a web application.

The main requirements for the software are based on the characteristics of sharing software like the one from "Opensourcebikeshare" [7] and general requirements.

Crucial properties of the software interacting with the users via a web application are a map with real time data about station proximity and bicycle availability, instructions and help for users, feedback from users, reward system for a balanced e-bike distribution. Additionally, it could have a routing tool if this is not integrated in the e-bicycle HID.

The GUI interacting with the administrators needs to provide data about system usage and provide a possibility to manage the fleet in real-time. This is possible via communication with RFID and GPS tracking devices or if you like on docks and bicycles as well as user feedback. Additionally, it will be connected to the battery charging machines which will provide data about battery state, such as number of cycles and usage patterns. 


\section{EleCtric BiCyCle RESEARCH AND DESIGN}

The above stated requirements have been applied on a development of a suitable electric bike. This involved researching an optimal bicycle design as well as a simulating power output and energy consumption during cycling to determine necessary motor and battery specifications.

\subsection{Bicycle Design}

Properties of bicycles in an average bike-sharing scheme are already a good approach to what a comfortable e-bike should look like. They are city-bikes with a step-thru frame, a rear rack for panniers or a basket mounted to the handlebars. With regards to cobblestone streets in Prague it is desirable to have some form of suspension. E-bikes with the same purpose should have a similar design except the design also involves a decision about where to place a motor and battery. The requirement of a minimal human effort includes optimal handling and steering behaviour of the bike. The centre of a mass of the rider-bike system affects this behaviour. In fact, the act of cycling is known to be a fairly complex mechanism. In addition to the rider's skill and gyroscopic forces, there are, acting on the wheel, the centre of gravity lowering torque and castoring forces [8]. In the context of this project we can simplify it by saying that keeping a bicycle from falling comes down to keeping the centre of mass of the rider-bike system over its wheels. At very low speeds or when coming to a halt, the bike is easier to handle with a low centre of mass because thanks to the the leverage, the rider also needs to apply relatively small forces on the handlebars to keep the bike upright.

From a certain minimum forward speed, it is easier to steer a bike with a higher centre of mass. F for the same reason it is easier to balance a tall broomstick on the end than a short pencil. The broomstick is a slower inverted pendulum for which one has more time to bring it back to balance[9]. On the other hand, as it is the case for normal bicycles, the mass of the rider still has the most impact on the overall centre of mass of the coupled electric bike - rider system. Thus for a placement of a battery and motor it is sufficient to look at handling behaviour at very slow speeds or standstill. Furthermore, taking in consideration the idea of transporting certain cargo on the rear rack it is preferable to have the battery weight inside the frame for a better mass distribution, for a minimal inertia high in the rear and thus for a safe and comfortable ride. The decision to choose a mid-drive motor contributes to this logic but is also a consequence of reasons stated in the next paragraph. Disadvantages of hub motors are an increased unsprang weight and a more difficult maintenance.

Apart from an extra mass added to the bicycle, the motor and battery need extra space. One idea on this matter is to use smaller wheels (24 to $18 \mathrm{inch}$ ) which are already often used in cargo bikes for this reason. Smaller wheels also lower the overall centre of the mass and enable higher acceleration amongst other advantages [10. One disadvantage is a decreased cushioning. A compromise could be only to have a smaller rear wheel.

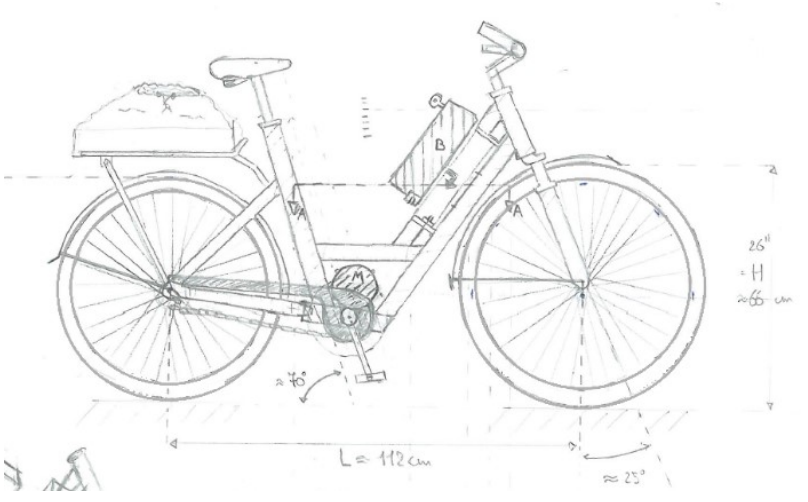

Figure 2. E-bike design: sketch by the writer, scale $1 / 10$.

To visualize the previously outlined ideas, the above draft of a possible e-bike design was sketched, keeping in mind low cost, easy fabrication for example with standard aluminum tubes. This draft could be a base for a more advanced (e.g. with integrated components) and attractive design that can be validated with a strength analysis.

A last point to look at is a protection against wind, rain and sunlight. There are some solutions on the market to solve this problem, such as detachable shields or poncho's. In case a full integration of this feature is opted, it is recognizable that the lower the rider sits to the ground the easier it is to design a cover/shield that protects a full body of the rider from the impact of precipitation and wind owing to its forward movement.

\subsection{Motor}

The main specification of an electric bike motor is its power. On the market the motors are distinguished by an electrical power they can infinitely continuously handle, for example "a 250 watt motor". This figue is misleading because of two reasons: the input power the motor uses is determined by the voltage of the battery multiplied by the current the controller draws from the battery (e.g. $36 \mathrm{~V} \times 15 \mathrm{~A}=540$ watt $)$. The motor will mostly be built for a certain voltage (e.g. a $36 \mathrm{~V} 250$ watt motor with a $36 \mathrm{~V}$ battery) so the maximum power will be proportional to a current limit in the controller. Secondly the electrical power is not equal to an output power on the axis of the motor because of internal losses. The latter one is the power assisting the rider in giving a bicycle a forward motion. The average efficiency $\eta$ of most motors on the market is around $80 \%$ at the optimal rpm so 350 watts into the controller will result in 280 watts of a driving power 11 . 
Minimal human effort and a possibility to transport certain cargo are the two initial requirements which come in to play when determining required motor power for this project. In other words, it can be stated that cycling should not be experienced as an exercise and the user can go from A to B in normal clothing without sweating (disregarding the influence of abnormal values for humidity and ambient temperature). The question is which human output power corresponds to this requirement. Professional cyclists can sustain 400 watts of leg power for an hour while for a person of an average health and fitness this would be 100 to 200 watts. These values apply for exercise till exhaustion[12. For a comfortable commuting a continuous human power output of 50 watts is decided to be a reasonable maximum. This amount is comparable to the power needed for a person of $80 \mathrm{~kg}$ to walk $1 \mathrm{~m} / \mathrm{s} 13$. The last steps in defining a necessary motor power consist first of all of specifying a required driving power for cycling as a function of speed $[\mathrm{km} / \mathrm{h}]$ and uphill slope [\%] and last of simulating required performances for cycling in Prague. At a constant speed the driver and motor combined have to overcome three forces:

(1.) Rolling resistance $\left(F_{\text {rol }}\right)$,

$$
F_{\text {rol }}=m_{\text {tot }} \times g \times C_{r}
$$

Where: $m_{\text {tot }}=$ mass of the rider-bike system, $g=$ gravitational acceleration $\left(9.81 \mathrm{~m} / \mathrm{s}^{2}\right)$ and $C_{r}=$ rolling resistance coefficient $( \pm 0.006$ for normal tire)

(2.) Aerodynamic resistance $\left(F_{a e r}\right)$,

$$
f_{\text {aer }}=\frac{1}{2} \times \rho \times v^{2} \times C_{W} \times A_{f}
$$

Where: $\rho=$ air density $\left( \pm 1.20 \mathrm{~kg} / \mathrm{m}^{3}\right.$ for $20^{\circ} \mathrm{C}$ and $1 \mathrm{~atm}), v=$ bicycle speed $[\mathrm{m} / \mathrm{s}], C_{W}=$ air resistance coefficient $( \pm 1.1$ for upright cyclist plus touring bike) and $A_{f}=$ frontal surface area (0.6 $\mathrm{m}^{2}$ for upright cyclist)

(3.) Inclination resistance $\left(F_{\text {incl }}\right)$,

$$
F_{\text {incl }}=m_{\text {tot }} \times g \times \sin \alpha
$$

Where: $m_{t o t}=$ mass of the rider-bike system, $g=$ gravitational acceleration $\left(9.81 \mathrm{~m} / \mathrm{s}^{2}\right)$ and $\alpha=$ is the inclination grade in degrees

then

$$
\begin{gathered}
F_{\text {tot }}=F_{\text {rol }}+F_{\text {aer }}+F_{\text {incl }} \\
P_{\text {driving,tot }}=F_{\text {tot }} \times v
\end{gathered}
$$

Assumption for $m_{\text {tot }}=m_{\text {driver }}+m_{\text {loadedbicycle }}=$ $75+35=110 \mathrm{~kg}$. All assumptions were made with a rather inefficient but still realistic set up in mind. The chosen parameter values are the result of a comparison of 12 and 14 .

On Figure 3 Power input during acceleration $=>$ from 0 to $25 \mathrm{~km} / \mathrm{h}$ in 3 seconds $=>F=m \times(v 2-v 1) / t$.



FiguRE 3. Driving power for speeds up to $50 \mathrm{~km} / \mathrm{h}$ and slopes up to $20 \%$.

Simulating cycling in Prague is a rather subjective process but as for a speed it is relevant to take $25 \mathrm{~km} / \mathrm{h}$ which is the maximum speed to which a motor can assist an electric bike by EU legislation.

It is known that Prague has uphill slopes up to $15 \%$ in the form of short streets. It is preferable these can be done with comfort and without the motor failing. With the above two values as a maximum the necessary driving power will be $1300 \mathrm{~W}$. EU legislation restricts a rated power to a maximum of $250 \mathrm{~W}$. In fact this stands for a $36 \mathrm{~V}$ motor with a $15 \mathrm{~A}$ controller which means this motor will be able to handle $540 \mathrm{~W}$ although not continuously. In the latter case the output power will average around $430 \mathrm{~W}$ which is far below a defined required driving power. As long as continuous comfort is more important for this project than a continuous speed, it is also useful to define a minimum speed. It was arbitrarily chosen to take $10 \mathrm{~km} / \mathrm{h}$, which is still a double of an average walking speed, as a minimum speed to go uphill.

Now the maximum necessary total driving power is $472 \mathrm{~W}$. Providing the rider takes $50 \mathrm{~W}$ on his behalf, the required motor input power becomes $(472-50) \times$ $100 / 80=527.5 \mathrm{~W}$. It can be recognised that a motor rated as $250 \mathrm{~W}$ is still insufficient, especially because at low speeds motor efficiency will be lower than $80 \%$ and the total mass might be higher.

There is a clear preference of a mid-drive motor to a wheel hub motor or a direct drive for implementation in a hilly city like Prague since a mid-drive motor can still work in (or closer to) the optimal rpm range at low speeds such as $10 \mathrm{~km} / \mathrm{h}$ provided a good use of the bicycle gears.

Present extensive e-bike testing and user experience will tell if this was a good simulation.

\subsection{BATTERY}

The battery is a fuel tank for an electric vehicle(EV). The required amount of energy it must store depends on energy consumed in a trip with a certain minimal range or minimal time. A range of 15 to $20 \mathrm{~km}$ is 


\begin{tabular}{|c|c|c|c|c|c|}
\hline $\begin{array}{l}\mathrm{v} \\
{[\mathrm{km} / \mathrm{h}]}\end{array}$ & $\begin{array}{l}\text { avgup } \\
\text { hill } \\
{[\%]}\end{array}$ & $\begin{array}{l}\text { distance } \\
{[\mathrm{km}]}\end{array}$ & \#accel & $\begin{array}{l}E_{\text {tot,el }} \\
{[\mathrm{Wh}]} \\
+ \text { hu- } \\
\text { man }\end{array}$ & $\begin{array}{l}E_{t o t, e l} \\
{[\mathrm{Wh}]} \\
\text { throt- } \\
\text { tle } \\
\text { mode }\end{array}$ \\
\hline 15 & 0 & 20 & 1 & 9.6 & 93.0 \\
\hline 20 & 0 & 20 & 1 & 67.8 & 130.3 \\
\hline 25 & 0 & 20 & 1 & 128.3 & 178.3 \\
\hline 25 & 0 & 40 & 1 & 255.9 & 355.9 \\
\hline 25 & 0 & 50 & 1 & 319.7 & 444.7 \\
\hline 25 & 2 & 5 & 1 & 70.1 & 82.6 \\
\hline 25 & 2 & 5 & 10 & 76.7 & 89.2 \\
\hline 25 & 2 & 5 & 20 & 84.1 & 96.6 \\
\hline 25 & 2 & 10 & 1 & 139.5 & 164.5 \\
\hline 25 & 2 & 15 & 1 & 208.8 & 246.3 \\
\hline 25 & 2 & 20 & 1 & 278.2 & 328.2 \\
\hline 25 & 2 & 30 & 1 & 416.9 & 491.9 \\
\hline 20 & 2 & 20 & 1 & 217.7 & 280.2 \\
\hline 10 & 5 & 5 & 1 & 79.0 & 110.2 \\
\hline 15 & 5 & 5 & 1 & 96.2 & 117.0 \\
\hline 20 & 5 & 5 & 1 & 110.9 & 126.5 \\
\hline 25 & 5 & 5 & 1 & 126.2 & 138.7 \\
\hline 10 & 10 & 1 & 1 & 34.5 & 40.7 \\
\hline 10 & 10 & 5 & 1 & 171.8 & 203.1 \\
\hline 15 & 10 & 1 & 1 & 38.0 & 42.2 \\
\hline 20 & 10 & 1 & 1 & 41.1 & 44.2 \\
\hline 20 & 10 & 5 & 1 & 203.7 & 219.3 \\
\hline 25 & 10 & 1 & 1 & 44.4 & 46.9 \\
\hline
\end{tabular}

TABLE 1. Estimated energy consumption within 23 different trips.

more than enough to cover an area that includes the center of Prague and the majority of CTU buildings. The electrical energy E consumed is equal to the time integral of electrical power $\mathrm{P}(\mathrm{t})$. If $\mathrm{P}=$ constant for certain time interval $\Delta t$, following expression applies:

$$
E_{\text {electric }}=P_{\text {elect }} \times t=\eta \times P_{\text {driv }, \text { mot }} \times t
$$

Assuming the same values for the rider-bike system as in the previous section the energy consumption in over 230 trips was simulated by setting discrete values for the following variables: velocity $[\mathrm{km} / \mathrm{h}]$ $(10,15,20,25)$, average uphill slope [\%] $(0,2,5)$, distance $[\mathrm{km}](1,3,5,10,15,20)$ and amount of accelerations at $1.388 \mathrm{~m} / \mathrm{s}^{2}(1,5,10)$. The table below (Table ?? shows some of the more relevant possible trips including scenarios that did not fall into the scope of the simulation.

The values in yellow show an effect on power and energy of changing this particular variable. The values in orange show trips with an energy consumption of more than $200 \mathrm{~W}$ in the throttle mode. The values in green show trips which are more typical for a bike sharing system $(<5 \mathrm{~km} \&<0.5 \mathrm{~h})$. The values in red show trips that require more than $650 \mathrm{~W}$ of an input power.
Taking into account that a deep discharge is to be avoided when trying to maximize a battery life span, it can be stated that 150 to $200 \mathrm{Wh}$ of a stored energy will be more than enough in the context of this project. Practically this could be a $36 \mathrm{~V} \times 6.6 \mathrm{Ah}$ or a $25 \mathrm{~V} \times$ $8 \mathrm{Ah}$.

The main specifications of a battery pack are voltage [V] and amp-hours [Ah]. The electrical energy storable in the battery pack can be estimated with this theorem:

$$
E_{\text {electric }}=V(t) \times I(t) \times t
$$

Where $V(t)=$ rated voltage of the battery pack [V] and $I(t) \times t=$ current discharge over time [Ah]. For the $36 \mathrm{~V}$ motor from the previous section and $300 \mathrm{Wh}$, equation $(7)$ gives a $36 \mathrm{~V} \times 8.3 \mathrm{Ah}$ (theoretical) battery. In practice, a battery pack is configured by a spot welding a number of cells in series and parallel e.g. $3.6 \mathrm{~V} \times 2200 \mathrm{mAh}$ cells in a 4 Parallel10Serie configuration makes a $36 \mathrm{~V} \times 8.8 \mathrm{Ah}$ battery pack. The number one chemistry for these cells is Lithium-ion e.g. LiFePO4 (IFR), LiCoO2 (ICR), LiMn2O4(IMR), LiNiCoAlO2 (INR), each with its own benefits and downsides. When optimizing this project, it will be highly relevant to compare these chemistries. For the latter examples it can be simplified by stating Li-manganese are especially safe, Li-iron-phosphate are the most economical (expensive but a high life span) and Li-cobalt have the highest specific energy but they need a good BMS to be safe 15. Another important property of a cell is its maximum continuous discharge rate. This rate is defined by its C-rate which expresses the time in which a battery can be discharged compared to its capacity in amp-hours, e.g. a $2 \mathrm{C}$ battery cell with $2200 \mathrm{mAh}$ can be discharged at $4400 \mathrm{~mA}$ in 30 minutes [16, 17. If the motor controller draws equal or more amps from the battery pack than its configuration can handle, this will result in a decreased capacity and probably also a decreased life span. In other words: if the e-bike is equipped with a $15 \mathrm{Amp}$ controller, a $2 \mathrm{C}$ rated battery will need to have at least $7.5 \mathrm{Ah}$ but preferably 10Ah. Thus, it can be stated that for this e-bike sharing project it is preferable to have a cell chemistry with a high C-rate since enough power is more important than a high capacity depending on what is an average distance between the stations and the characteristics of an average trip.

A standard size for these cells is 18650 (18mm diameter, $65 \mathrm{~mm}$ long, round shape) and their weight is a little less than $50 \mathrm{~g}$. A charging rate is mostly between $0.5 \mathrm{C}$ and $1 \mathrm{C}$ e.g. a $8.8 \mathrm{Ah}$ battery pack charged at $2 \mathrm{~A}$ will take about 5-6 hours to be fully charged. Note that it will take about as much time to charge a battery from 0 to $80 \%$ as from $80 \%$ to $100 \%$. It was the case in the "CycleUshare" project that the batteries were made available by the system from the moment they were $75 \%$ charged which increased efficiency but still a reasonable range 18 . 


\subsection{EleCtronics}

Just like the system itself is required to be intelligent, so much is the e-bike itself. Via a GUI on the handlebars the rider can be informed about multiple variables as speed, trip distance, trip time, instantaneous power input and battery capacity, etc. More advanced devices as the Cycle Analyst will also provide information about Wh or Ah consumed, estimated Wh left (instead of the typical battery icon) and an amount of human power amongst other variables. If a GPS tracker is built in and a logging device is installed on the bike it is possible to carry out full post trip analyses which are interesting for further research in this project. Using a mid-drive motor, it is preferable to have a gear sensor that cuts off motor power momentarily when the user shifts gears, thereby preventing too much stress on the chain and the gearing system which causes rough gearing and can cause damage as well. A better but more expensive solution would be a continuously variable transmission (CVT). The motor is mostly controlled with hall sensors. There are three main ways the rider can get assistance from the motor: throttle mode (current flow is proportional to angle of (thumb) throttle), cadence based pedal assist (current flow is proportional to crank rotation speed), torque based pedal assist (current flow is proportional to amount of torque exerted on the chain or the pedals). From these three ways the latter feels the most intuitive while the cadence based PAS is much cheaper and thus more common. Another advantage of torque proportional assistance is an increased battery range 19. To achieve the proclaimed $50 \mathrm{~W}$ of human power at all speeds and slopes a torque sensor would be ideal. In practice this can be done with a chain tension sensor or a strain gauge on the cranks or pedal axles. Usually the HID offers a chance to set different PAS levels so the user can choose how much proportional assistance he or she requires from the motor.

Most battery packs on the market will have a Battery Management System (BMS) which is a circuitry to keep individual cell voltages balanced during charging and discharging. Furthermore, it protects the cells from different circumstances such as high temperatures, deep discharge and overcharging. The quality and intelligence of this BMS will have a high impact on the life span of a battery pack and depending on the chosen cell chemistry the BMS is essential for safety, more specifically for preventing fires or explosions.

\section{E-BIKe BUILDing, TESTing AND RESULTS}

\subsection{Choosing a Configuration}

Due to a low initial budget it was decided to convert a normal bicycle to an e-bicycle with a commercially available mid-drive kit and a downtube battery. Because this battery requires presence of water bottle cage mounting holes it was more convenient to buy a male framed bicycle (see Figure 4).



Figure 4. Photo of an assembled e-bike.

The configuration of the research bike consisted of a $350 \mathrm{~W}$ rated mid-drive motor, meaning a $36 \mathrm{~V}$ motor with $18 \mathrm{~A}$ controller, i.e. a peak input power of $648 \mathrm{~W}$. The battery pack has a capacity of $36 \mathrm{~V} \times 8.8 \mathrm{Ah}$ which is a 4P10S configuration of Samsung ICR18650$22 \mathrm{P}$ cells $(3.62 \mathrm{~V} \times 2150 \mathrm{mAh})$. Samsung claims these cells have a maximum continuous discharge rate of $3 \mathrm{C}$ which means $26.4 \mathrm{~A}$. In fact, discharging at $3 \mathrm{C}$ the battery will already put quite some stress on the cells and the capacity will be lower due to heat losses as can be seen on discharge curves of this particular cell[7].

\subsection{Tests And Results}

Firstly, the balancing of the e-bike was found very easy. One indicator for this is that it was very easy to balance the bike without hands on the handlebar. The bike enabled flexible maneuvering. This proves the chosen placement of battery and motor to be correct.

Secondly acceleration, top speed in the throttle mode was up to $34 \mathrm{~km} / \mathrm{h}$ on a flat in an upright position. The accelerations perceived a big difference with normal cycling. The ease of getting up to speed was so easy both with the pedal assistance and the throttle mode is similar to riding a scooter or a small motorcycle.

The motor did tend to heat up quite quickly after riding the bike several minutes in the highest PAS levels (4 and 5). This shows that the set up with $36 \mathrm{~V}$ and $18 \mathrm{~A}$ the limit approaches the level a motor with these 62 dimensions can handle. The same motor is rated " $250 \mathrm{~W}$ " with a $15 \mathrm{~A}$ current limit, in this case the motor will probably not heat up as much, combined with less stresses on the plastic gears inside. It might therefore have a longer lifespan with $15 \mathrm{~A}$ maximum.

Riding in Prague with this e-bike also revealed possible dangers, mostly concerning the higher speeds achievable. Being very vulnerable on an e-bike speeds tended to drop when riding among car traffic. 
Another inconvenience is that not being able to go to a lower gear at low speeds or standstill feels rather unhandy regarding smooth accelerations. This is not any different with normal bikes but with this e-bike there was a tendency to prevent shifting too much and staying in a high gear for higher speeds. Because the brakes cut off the motor power there is no need to go down in gears when slowing down and coming to a stop. Although the electric motor can handle starting in the highest gear, the acceleration at lower gears is more logical, but shifting to a lower gear at standstill causes much stress on the gearing system and is perceived unsmooth.

\section{EXPERIMENTS}

\subsection{FIRST EXPERIMENT}

For last three years two experiments have been carried out with the e-bike for transportation among the three buildings of CTU. These two experiments have been performed by students of the project Electromobility. The bikes for the experiments were borrowed with similar or lower configuration as the bicycle, which was constructed.

The first experiment covered the connections between the three buildings of CTU. In this project only students of CTU were included. In every buildings there was a spot for borrowing an e-bike, where the students borrowed the e-bike and rode to another building of CTU, where they returned the e-bike. During the trips the students measured parameters of the trip by mobile application and sent data to the folder for processing.

In 15 days there were made about 50 rides and every ride proved that transport by e-bike among buildings is faster than other types of transport, such as automobile or public transport 20 .

\subsection{SECOND EXPERIMENT}

The second experiment was made in 2014, and it examined advantages and parameters of riding the e-bike to the center of Prague from an outskirt of the city.

For this experiment typical trips for riding to center of Prague were chosen, the center was selected as the building of CTU Horská. There were 10 trips and every measuring showed that every trip is faster by e-bike opposite to the car or public transport. Only one trip, the trip of about 10 kilometers, was faster by metro than e-bike[21].

\subsection{EXPERIMENTS CONCLUSION}

The e-bike constructed for this thesis and presented in this article, was tested only for the driver's comfort and for technical parameters, but not for measuring parameters and comparison with another type of transport.

The previous two experiments were only for testing e-bikes as a means of transport for students among the buildings of CTU or for transporting students from home to school. It should start as a private public transport for students in "campuses", with private spots for rental and private system of borrowing and security. In the future, it would be beneficial to add new places, such as the Central Station, where it can be extended to general public which will help to make the system more popular among general population and tourists.

\section{Conclusion}

It is clear that e-bike sharing is a useful technology which can be a transportation method made ready to fit to a wide range of possible users.

However, the small portion of real world examples show the concept still faces some difficulties, most of which being financial or organizational ones. Thus, it is important to plan implementation and exploitation thoroughly with all stakeholders involved in the debate with a strong business plan laid on the table.

The research e-bike, equipped with the Cycle Analyst and logger can be used to acquire accurate data about energy consumption and other trip characteristics when e-cycling in Prague meanwhile experimenting with different types of bicycles, installing wind and rain shields or full covers to see their effect on energy consumption and comfort. As a result, the developed e-bike can be optimized further and fabricated.

Specific recommendations for further successful realization of the e-bike sharing project:

- Set up a strong business plan by means of a user survey and investment analysis and specific action plans.

- Further visualize the final result by implementing a (3D) design of both station and e-bike.

- Cooperate with other institutions and faculties.

- Set up an organization which will manage this interdisciplinary project and represent it.

These 4 recommendations will significantly help with the challenge of an increasing student interest and involvement and increasing interest from sponsors, advertisement companies, university management and city municipalities. According to the market studies Prague manages to keep up with the trends and efficient modes of transport. E-bike sharing could be then very soon visualized in Prague at CTU.

\section{REFERENCES}

[1] "European bicycle market analysis 2015", Advocacy means sales, European Cyclists' federation. Edited by: Alexander Scholz, published on 25.08.2016.

[2] "Gobike", Gobike. [Online], Available: http://gobike.com/solution/the-bike/, [Geopend 10 May 2016].

[3] "Bewegen", Bewegen Technologies Inc. [Online], Available: http://bewegen.com/our-system/\#top [Geopend 10 May 2016]. 
[4] "Bonopark", Bonopark. [Online], Available: http://www. bonopark.es/en. [Geopend 10 May 2016].

[5] "CycleUshare", University of Tennessee. [Online], Available: http://www.cycleushare.com/, [Geopend 10 May 2016].

[6] "itdp", the Institution of Transportation and Development Policy. [Online], Available: https://www.itdp.org/wp-content/uploads/2014/ 07/ITDP-Bike-Share-Planning-Guide-1.pdf, [Geopend 10 May 2016].

[7] "Open source bike share". [Online], Available: http://opensourcebikeshare.com/, [Geopend 25 May 2016].

[8] D. E. Jones. The stability of the bicycle. Physics Today. Pp. 34-40, 1970.

[9] J. M. J. P. A. R., A. J. D. G. Kooijman. A bicycle can be self-stable without gyroscopic or caster effects. Science, no. 332, pp. 339-342, 2011.

[10] T. Hadland. Small Wheels for Adult Bicycles. 25 June 2012. [Online], Available:

https://hadland.wordpress. com/2012/06/25/ small-wheels-for-adult-bicycles/, [Geopend 25 May 2016].

[11] J. Lemire-Elmore. ebiks.ca. Grin Technologies. [Online], Available: http://www.ebikes.ca/tools/simulator.html, [Geopend 28 April 2016].

[12] M. Ikonen. Ip-zev. 2 April 2011. [Online], Available: http://www.ip-zev.gr/files/teaching/T4-2_Human_ power.pdf, [Geopend 28 April 2016].

[13] D. J. Farris, G. S. Sawicki. ncbi. PMC, 25 May 2011. [Online], Available: http://www.ncbi.nlm.nih.gov/ pmc/articles/PMC3223624/table/RSIF20110182TB1/, [Geopend 28 April 2016].
[14] "Coefficient of friction, Rolling resistance and Aerodynamics", Tribology-abc. [Online], Available: http://www.tribology-abc.com/abc/cof.htm\# rolweerstand, [Geopend 30 May 2016].

[15] "Battery chemistry finally explained", Battery Bro, 19 February 2015. [Online], Available: https://batterybro.com/blogs/ 18650-wholesale-battery-reviews/ 18880255-battery-chemistry-finally-explained [Geopend 26 May 2016].

[16] "Batteries", Grin Technologies. [Online], Available: http://www.ebikes.ca/learn/batteries.html, [Geopend 26 May 2016].

[17] "BU-402: What Is C-rate?", Battery University, 29 February 2016. [Online], Available: http://batteryuniversity.com/learn/article/ what_is_the_c_rate, [Geopend 27 May 2016].

[18] C. R. Cherry, S. Ji, L. D. Han, D. A. Jordan. Electric bike sharing: simulation of user demand and system. Journal of Cleaner Production. Vol. 85, pp. 250-257, 2014.

[19] "Torque sensors on Electric bikes", ectricbike.com, 18 October 2012. [Online], Available: http://www.electricbike.com/torque-sensors/ [Geopend 27 June 2016].

[20] M. Lapáčková. Bike sharing na Fakultě dopravní. Praha, 2014, Diplomová práce. ČVUT FD.

[21] L. Jáneš. Využití elektrokol v Praze z hlediska bezpečnosti a členitosti terénu. Praha, 2015, Bakalářská práce. ČVUT FD. 